\title{
Editorial: The Public Health Needs for an Ageing Society
}

\author{
Linda P. Fried, MD, MPH, ${ }^{1}$ \\ Fred Paccaud, MD, $\mathrm{MSc}^{2,3}$
}

Population ageing is the sought-for outcome of improved public health, education and medical care over the last century. Worldwide, life expectancy is increasing. The health with which people age, given longer lives, has become a critically important determinant of population health and of development agendas as well as the economic well-being of nations. This issue of Public Health Reviews is devoted to the description and the analysis of how increased life expectancy and ageing affect population needs and compel us to modify public health science and leadership. It lays out the transitions in population science and the multilevel public health and policy agenda for the future necessary to support longer lives that are healthy and engaged.

The public health consequences of longevity and population ageing do not come as a surprise. The emergence of ageing as a public health issue dates back to the mid- $20^{\text {th }}$ century. The demographic transition (as originally expressed in the 1920's by Warren Thompson) predicted an increase in the proportion of aged people in the post-transitional period, i.e., as a result of the combination of low mortality and low birth rate. The link between the demographic transition and population health was further characterized by Omran in the 1970's. ${ }^{1}$ The so-called epidemiologic transition characterizes the secular change between two epidemiological stages, i.e., from high fertility and a high, unstable frequency of rapidly lethal infectious diseases to a new situation of low fertility and health issues dominated by slowly progressing chronic and degenerative diseases. Cardiometabolic disease, cancer, neuropsychiatric diseases and musculo-skeletal conditions are now predominant (or will be soon) in most parts of the world. ${ }^{2}$

Several current observations were, however, unexpected. One is the ever-increasing longevity in most high income countries. ${ }^{3}$ Mortality is low,

\footnotetext{
${ }^{1}$ Columbia University Mailman School of Public Health, New York

${ }^{2}$ Institute for Social and Preventive Medicine, University Hospital Center and Faculty of Biology and Medicine, Lausanne

${ }^{3}$ Swiss School of Public Health, Zurich
} 
and the rate is decreasing at a sustained pace, mainly among the elderly and very elderly populations. The second is the substantial benefits associated with prevention and health promotion into the oldest ages. ${ }^{4}$ The third is that healthy ageing is critical to experiencing the benefits of an ageing society, and key to the public health agenda of the future. ${ }^{5,6}$

Most high income countries have had a relatively long period of time to adapt their health systems to this epidemiologic transition. Progress has been slow and the changes are still incomplete. However, the pace of this adaptation was possible due to the relatively slow pace of population transition in these countries. Transitions have been eased by the large amount of resources made available to healthcare in the second part of the $20^{\text {th }}$ century in the most developed countries.

This situation does not apply to most low and middle income countries, where both demographic and epidemiologic transitions are much more rapid. This accelerated pace of population ageing combined with the persistence of longstanding public health problems related to transmissible diseases and maternal and child health have left little time until now to address the necessity to rethink and to reorganize health systems. The resources that need to be developed are, in part, financial. However, they must also include powerful public health science, planning, an appropriately designed health system as well as an appropriately trained public health and healthcare workforce. The latter, in general, are insufficient in number and not well prepared to offer adequate prevention and cost-effective care for non-communicable chronic diseases, such as diabetes, Parkinson's disease or stroke and heart disease, the disability resulting from disease or frailty or the conditions associated with physiological aging or the consequences of multimorbidity.

The Madrid Convention of 2002 emphasized that the ageing of the population must be embraced as an opportunity for developing countries, and that addressing the needs of older adults in an ageing society must be at the heart of economic development agendas, and is necessary to allow society to experience the benefits that an ageing population can offer. ${ }^{7}$ There is increasing evidence that longevity improves economic development and wealth; however, to reap the benefits, society must invest in healthy ageing and adapt societal institutions to fit the needs of an ageing society. ${ }^{8,9} \mathrm{~A}$ similar challenge exists for developed countries, although with perhaps different needs; these countries, too, would benefit from harnessing the opportunities associated with population ageing. In fact, healthy ageing is becoming a necessity for maintenance of a productive workforce. As the population ages, so does the workforce: for example, between 1995 and 2000, 
the number of physicians under 45 years of age across Europe dropped by 20 percent while the number over 45 increased by over 50 percent. In five European Union member states, nearly half the nurses are over 45 years old. ${ }^{10}$ The strategy of raising the retirement age will only succeed if people age healthfully.

Thus, at the heart of experiencing the benefits of our longer lives is the challenge of helping individuals and populations stay healthy across the entire life course. This is a critical challenge for public health. A high and still increasing longevity currently means an elevated absolute prevalence of degenerative disease, i.e., an increase of needs and demands for chronic care and sustained prevention. This is a challenge for health systems, most of which have been organized to face epidemics of transmissible diseases and to treat acute episodes of individual diseases. Preventing individual diseases, falls, frailty, disability and multimorbidity, or taking care of people with coexisting cardiac failure, Parkinson's disease and arthritis requires new science, new knowledge and different approaches to prevention and care.

At the level of health systems, ageing of the population and its health consequences require new perspectives for prevention, including primary, secondary and tertiary prevention of diseases, geriatric conditions (such as frailty and falls), and disability, along with better integration of prevention into health systems. ${ }^{5}$ Prevention is a key issue as well in terms of keeping health systems economically feasible and affordable.${ }^{11,12}$ Preventing avoidable degenerative diseases is necessary to keep resources available to treat diseases that cannot be prevented, and to improve healthy ageing and societal productivity and well-being at all ages.

This issue of Public Health Reviews offers multidimensional information and some refreshing ideas on the topics described above. It addresses the multilevel approaches needed to support longer lives that are healthy and active: from life course approaches to prevention to redesign of our built environment and our institutions to support activity and independence, to adapting our health systems to provide prevention and care that better matches the health needs of people with multimorbidity - and likely at lower cost. The paper by Isabella Aboderin appropriately summarizes the policy challenges faced by sub-Saharan Africa, ${ }^{13}$ which has both the fastest growing elderly population of any world region and the substantial persistence of classical tropical diseases, in addition to an increasing superimposition of chronic non-communicable diseases. The case report by Alban Ylli from Albania describes the situation of an already-aged society in which substantial unmet needs exist for older adults. ${ }^{14}$ Marc Suhrcke, et al. address the macroeconomics of ageing in a carefully 
balanced paper. ${ }^{15}$ Expectedly, several articles are devoted to prevention, with Liu, Jones and Glymour, and Toni Antonucci and Kristin Wong providing synthetic analyses of life course approaches to prevention from the lens of the individual, society and families ${ }^{16,17}$; Abby King and Diane King on improving and enhancing physical activity in ageing populations ${ }^{18}$; John Beard and Charles Petitot on urban design to create age-friendly cities $^{19}$; and Will Maimaris, et al. on the relationship between retirement and mental health. ${ }^{20}$ Fundamental issues bringing gerontologic concerns into public health science are addressed by Luigi Ferrucci with a discussion on frailty ${ }^{21}$ and by Cynthia Boyd and Martin Fortin on how prevalence of multimorbidity necessitates different approaches by health systems. ${ }^{22}$

Because chronic disease prevention across the life course is critical to healthy aging, while age-specific approaches are needed to the oldest ages, an upcoming issue of Public Health Reviews will be dedicated to these critical issues.

Overall, this unprecedented human experience of longer lives offers opportunities for individuals, families and societies, which can have great advantages for all. Essential to reaping the harvest of our longer lives is the redefinition of public health, prevention and system approaches to support health across the life course, for every age and at every stage. Public health strategies, designed for older adults and for longer lives, involving cities and social institutions, will be good for all.

\section{REFERENCES}

1. Omran AR. The epidemiologic transition. A theory of the epidemiology of population change. Milbank Mem Fund Q. 1971;49:509-38.

2. World Health Organization. 2008-2013 Action Plan for the Global Strategy for the Prevention and Control of Noncommunicable Diseases. (2009). Available from URL: http://www.who.int/nmh/publications/9789241597418/en/index. html (Accessed 28 January 2011).

3. Christensen K, Doblhammer G, Rau R, Vaupel JW. Ageing populations: the challenges ahead. Lancet. 2009;374:1196-208.

4. Bloom D, Canning D. The health and wealth of nations. Science. 2000;287:1207-9.

5. Fried LP. What are the roles of public health in an aging society? In: Prohaska TR, Anderson LA, Binstock RH, editors. Public health for an aging society. Baltimore, (MD): Johns Hopkins University Press; in press.

6. Rowe JW, Kahn RL. Successful aging. Aging (Milano). 1998;10:142-4.

7. United Nations. Report of the Second World Assembly on Ageing. (8-12 April, 2002). Available from URL: http://www.un.org/ageing/madrid_declaration02. html (Accessed 7 December, 2010). 
8. Fried LP, Carlson MC, Freedman M, Frick KD, Glass TA, Hill J, McGill S, Rebok GW, Seeman T, Tielsch JM, Wasik B, Zeger S. A social model for health promotion for an aging population: initial evidence on the Experience Corps ${ }^{\circledR}$ model. J Urban Health. 2004;81:64-78.

9. Fried LP, Freedman M, Endres TE, Wasik B. Building communities that promote successful aging. WJM. 1997;167:216-9.

10. Commission of the European Communities. Green paper On the European Workforce for Health. (10 December, 2008). Available from URL: http://ec. europa.eu/health/ph_systems/docs/workforce_gp_en.pdf (Accessed 28 January, 2011).

11. Butler, RN, Miller RA, Perry D, Carnes BA, Williams TF, Cassel C, Brody J, Bernard MA, Partridge L, Kirkwood T. Martin GM, Olshansky SJ. New model of health promotion and disease prevention for the 21 st century. BMJ. 2008;337:a399.

12. Nolte E, McKee M. Caring for people with chronic conditions: a health system perspective. European Observatory on Health Systems and Policies Series. Maidenhead, (UK): McGraw Hill Open University Press; 2008.

13. Aboderin I. Understanding and advancing the health of older populations in sub-Saharan Africa: Policy perspectives and evidence needs. Pub Health Rev. 2010;32:357-76.

14. Ylli, A. Health and social conditions of older people in Albania. Baseline data from a national survey. Pub Health Rev 2010;32:549-61.

15. Suhrcke M, Fumagalli E, Hancock R. Is there a wealth dividend of aging societies? Pub Health Rev. 2010;32:377-400.

16. Liu S, Jones RN, Glymour MM. Implications of lifecourse epidemiology for research on determinants of adult disease. Pub Health Rev. 2010;32:489-511.

17. Antonucci TC, Wong KM. Public health and the aging family. Pub Health Rev. 2010;32:512-31.

18. King AC, King DK. Physical activity for an aging population. Pub Health Rev. 2010;32:401-26.

19. Beard JR, Petitot C. Ageing and urbanization: Can cities be designed to foster active ageing? Pub Health Rev. 2010;32:427-50.

20. Maimaris W, Hogan H, Lock K. The impact of working beyond traditional retirement ages on mental health: Implications for public health and welfare policy. Pub Health Rev. 2010;32: 532-48.

21. Ferrucci L, Hesdorffer C, Bandinelli S, Simonsick EM. Frailty as a Nexus Between the Biology of Aging, Environmental Conditions and Clinical Geriatrics. Pub Health Rev. 2010;32:475-89.

22. Boyd CM, Fortin M. Future of multimorbidity research: How should understanding of multimorbidity inform health system design? Pub Health Rev. 2010;32:451-74. 